\title{
Взаимосвязь профессионально важных качеств и успешности профессиональной деятельности у специалистов Государственной инспекции по маломерным судам МЧС России
}

\author{
Юлия С. Шойгу, Анастасия А. Тарасова* \\ Федеральное казенное учреждение «Центр экстренной психологической помощи \\ МЧС России», г. Москва, Российская Федерация \\ *E-mail: tvsova80@mail.ru
}

\begin{abstract}
Аннотация
Введение. Аанная статья является продолжением ранее выполненного авторами исслеАования по вылелению профрессионально важных качеств ( $\triangle$ алее - ПВК) у инспекторов Государственной инспекции по маломерным судам (Аалее - ГИМС МЧС России). Целью исслеАования является определение взаимосвязи вылеленных ПвК у инспекторов ГИМС МЧС России и успешности выполнения продрессиональной АеятеАьности ранее обследованных специалистов. Новизна исслеАования состоит в том, что ввиАу неАостаточности в настоящее время эмпирических $А$ анных установлены значимость

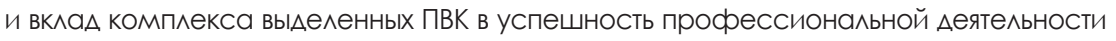
инспекторов ГИМС МЧС России, которые являются преАпосылками к фрормированию еАиного методологического подхода в рамках каАровой и психологической работы по отбору на АОАжность Инспектора ГИМС МЧС России.
\end{abstract}

Методы. В рамках исслеАования бы^ осуществлен поАбор психоАиагностического инструментария, с помощью которого провеАено обслеАование инспекторов ГИМС МЧС России. А^я определения эфрорективности деятельности обследуемых бы^ использован метол экспертного опроса с послеАующей статистической обработкой полученных Аанных: по результатам опроса были получены оценки по успешности выполнения профрессиональной Аеятельности на кажАого обслеАуемого с Аальнейшим получением интегральной экспертной оценки, являющейся внешним критерием успешности продрессиональной Аеятельности инспекторов ГИМС МЧС России.

Результаты. Анализ результатов исследования позволил заключить, что вылеленные ПВК инспекторов ГИМС МЧС России обуславливают успешность их продеессиональной Аеятельности. В то же время весь комп^екс ПвК способствует более эфорективному выполнению профеессиональной Аеятельности инспекторами ГИМС МЧС РОсСИи, чеМ ПВК пО ОТАЕАьнОсти.

ОбсужАение результатов. САелан вывод о том, что ранее выАеленные ПВК можно считать критерием прогнозирования успешности професссиональной Аеятельности инспекторов ГИМС МЧС России. ИсслеАование имеет приклалной характер, 
пСИхолОГИЯ ТРУДА

заключающийся в использовании полученных результатов при проведении профеессионального психологического отбора на Аолжность инспектора ГИМС МЧС России с целью снижения негативных психологических послеАствий, психосоматических и Аругих заболеваний, связанных с профессиональной Аеятельностью.

\title{
КАючевые слова
}

инспектор, успешность профрессиональной Аеятельности, эфрфеективность профессиинальной Аеятельности, профессионально важные качества, экспертный опрос, экспертная оценка, взаимосвязь, прогнозирование успешности, корре^яционный анализ, статистическая Аостоверность

\section{Основные положения}

- важным компонентом успешного выполнения профрессиональной Аеятельности инспекторов ГИМС МЧС России являются ПВК;

- внешним критерием успешности выполнения профрессиональной Аеятельности инспекторов ГИМС МЧС России является интегральная экспертная оценка; - структура ПВК и связь межАу выАеленными ПВК влияют на успешность выполнения профрессиональной Аеятельности инспекторов ГИМС МЧС России.

\section{Для цитирования}

Шойгу Ю.С., Тарасова А. А. Взаимосвязь профессионально важных качеств и успешности профессиональной деятельности у специалистов Государственной инспекции по маломерным судам МЧС России // Российский психологический журнал. - 2018. T. 15, № 1. - C. 113-139. DOI: 10.21702/rpj.2018.1.6

Материалы статьи получены 01.12.2017

UDC 159.9.072.592

DOI: 10.21702/rpj.2018.1.6

\section{Professionally Important Qualities and Professional Achievement Among Inspectors in the State Small Vessels Inspectorate of EMERCOM of Russia}

\section{Julia S. Shoigu, Anastasia A. Tarasova*}

Center for Emergency Psychological Aid, EMERCOM of Russia, Moscow, Russian Federation * Correspondence author. E-mail: tvsova80@mail.ru

\begin{abstract}
Introduction. This paper continues a previous study on professionally important qualities of inspectors in the State Small Vessels Inspectorate (SSVI) of EMERCOM
\end{abstract}




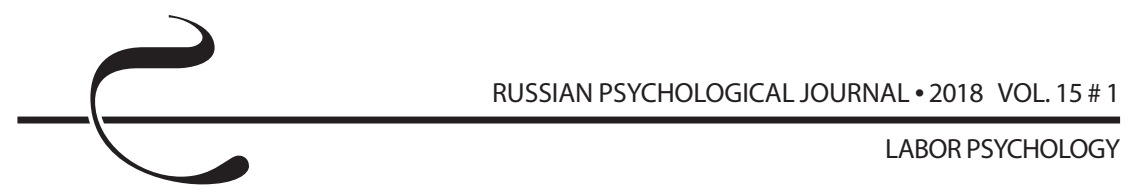

of Russia. Professionally important qualities contribute to professional achievement among inspectors in the SSVI of EMERCOM of RUssia. This is a prerequisite for a unitary methodological approach to the selection of a candidate for a position of an inspector in the SSVI of EMERCOM of Russia. The aim of the study is to determine the relationships among professionally important qualities of inspectors in the SSVI of EMERCOM of Russia and professional achievement among the surveyed specialists.

Methods. An expert survey and statistical treatment of data helped to measure professional achievement. The survey revealed assessments of professional achievement for each participant. An integral expert assessment was an external criterion for professional achievement among inspectors in the SSVI of EMERCOM of RUssia.

Results. The results indicated that professionally important qualities of inspectors in the SSVI of EMERCOM of Russia determined their professional achievement. At the same time the whole complex of professionally important qualities promoted more effective performance of professional activities.

Discussion. The previously revealed professionally important qualities can predict professional achievement among inspectors in the SSVI of EMERCOM of Russia. The findings can be readily used in professional psychological selection for the position of an inspector in the SSVI of EMERCOM of Russia in order to reduce negative psychological consequences, psychosomatic and other diseases associated with professional activities.

\section{Keywords}

inspector, professional achievement, efficiency of professional activities, professionally important qualities, expert survey, expert evaluation, relationship, prediction of achievement, correlation analysis, statistical significance

\section{Highlights}

- Professionally important qualities are important for professional achievement among inspectors in the SSVI of EMERCOM of Russia.

- An integral expert assessment is an external criterion for professional achievement among inspectors in the SSVI of EMERCOM of Russia.

- Relationships among professionally important qualities and their structure affect professional achievement among inspectors in the SSVI of EMERCOM of Russia.

\section{For citation}

Shoigu Ju. S., Tarasova A. A. Professionally Important Qualities and Professional Achievement Among Inspectors in the State Small Vessels Inspectorate of EMERCOM of Russia. Rossiiskii psikhologicheskii zhurnal - Russian Psychological Journal, 2018, V. 15, no. 1, pp. 113-139 (in Russian). DOI: 10.21702/rpj.2018.1.6

Original manuscript received 01.12.2017 


\section{Введение}

В современном мире научно-технического прогресса происходит зарождение новых профессий, требующих и специальных профессиональных навыков, и качеств личности. Это, в свою очередь, можно со всей уверенностью отнести и к профессии инспектора ГИМС МЧС России. Данный вид профессиональной деятельности относится к редким; также отсутствуют высшие учебные заведения по подготовке специалистов по данному профилю, что, в свой черед, может сказываться на профессионализме, компетентности и психологической готовности к данному виду деятельности.

Любая профессиональная деятельность характеризуется присущими ей особенностями - окружением, обстановкой, условиями труда и отдыха, объектом и предметом труда. Успешность овладения профессиональной деятельностью, прежде всего, зависит от понимания работниками ее содержания. Для этого необходимо получить знания по данной профессии и определенный опыт. Формирование четкого представления об успешности профессиональной деятельности является важным и для специалистов экстремального профиля, к которым относится и деятельность инспектора ГИМС МЧС России.

Профессиональная деятельность инспектора ГИМС МЧС России рассматривается как вид трудовой деятельности по выполнению функций надзора, контроля, соблюдения тех или иных правил и норм в пределах своей компетенции. В то же время данный вид профессиональной деятельности связан с полифакторным стрессовым воздействием, связанным не только с взаимодействием с людьми, органами местного самоуправления в части, касающейся преподавания основ безопасности на воде и эксплуатацией плавательных средств, пляжей, лодочных переправ и баз стоянок судов, но и с работой в сложных гидрометеорологических условиях, связанных с напряжением и угрозой собственной жизни и здоровью. Особое значение для инспекторов ГИМС МЧС России имеют такие особенности, которые влияют на их профессиональную деятельность, - те, от которых зависит результат выполняемых трудовых функций. В связи с этим можно с уверенностью сказать, что профессия инспектора ГИМС МЧС России связана с такими видами деятельности, как: операторская, документационная, контролирующая, организаторская, исследовательская, аналитическая, консультативная, педагогическая, коммуникативная. По результатам анализа изучения деятельности профессиональных контингентов МЧС России было установлено, что в практической сфере всех специалистов МЧС России не уделяется внимания психологическому фактору успешности деятельности инспекторов ГИМС МЧС России, основанному на степени реализации индивидуальных психических качеств с выполнением функциональных обязанностей. 
Таким образом, целью исследования является определение взаимозависимости профессионально важных качеств и успешности профессиональной деятельности у инспекторов ГИМС МЧС России.

\section{Анализ литературы по тематике исследования}

Люди обладают различными психологическими и психофизиологическими качествами. Некоторые сочетания таких свойств и качеств способствуют успешной работе, а другие, наоборот, могут препятствовать. При этом важными условиями, которые оказывают влияние на профессиональную успешность, являются как способности, так и психологические качества человека. Рассмотрение разнообразных факторов, детерминирующих успешность профессиональной деятельности, говорит о важности определения влияния как самой деятельности, так и характеристик субъекта деятельности в их взаимном воздействии $[1,2,3,4]$. Проблема взаимосвязи психологических особенностей личности и деятельности освещена в ряде работ как отечественных, так и зарубежных исследователей - Б.Г. Ананьева, Б.С. Братуся, Л.С. Выготского, Е.А. Климова, И.С. Кона, Л.Ф. Обуховой, Э. Эриксона и др. [5, 6, $7,8,9,10,11]$.

Успешность деятельности является одной из важных характеристик любой профессиональной деятельности. При этом четкое, общепризнанное представление о критериях оценки деятельности отсутствует [12].

Успешность выполнения профессиональной деятельности заключается не только в скорости, безошибочности действий, производительности труда, но и в психофизиологических изменениях со стороны организма человека, которые необходимы для выполнения трудовой деятельности. При этом успешность деятельности связана как с разнообразными сферами личности (интеллектуальной, эмоциональной, волевой, мотивационной), так и с индивидуальными психофизиологическими особенностями субъекта деятельности [13]. Однако успешность выполнения профессиональной деятельности и эффективность деятельности не являются однопорядковыми категориями [14].

Эффективность деятельности - более узкое понятие, означающее отношение достигнутого результата к максимальному достижимому или заранее запланированному результату, определяющее результативность выполнения действий в реальной рабочей обстановке со всеми возможными усложнениями ситуации, включая экстремальные условия. Основными характеристиками эффективности деятельности являются качество и производительность [13].

Следовательно, говоря об эффективности деятельности, мы подразумеваем и ее успешность. 
Единая оценка успешности профессиональной деятельности, по мнению многих исследователей, должна иметь как внешнюю, так и внутреннюю составляющую.

В.А. Толочек определяет успешность как интегральный феномен, который оценивается: во-первых, по качеству и производительности труда, описанным в документах; во-вторых, по административным актам, отражающим дисциплинарные взыскания и продвижения по службе; в-третьих, по внешней оценке успешности деятельности работника, даваемой руководителями, коллегами, клиентами; в-четвертых, по внутренней оценке эффективности, получаемой от самого субъекта труда [15].

По мнению М.А. Дмитриевой, профессиональная успешность состоит из безошибочности действий, результативности выполняемой деятельности, качества получаемых результатов. При этом автор обращает внимание на то, что важны и такие качества, как нервно-психические затраты человека при выполнении деятельности и удовлетворение, которое испытывает работник в процессе трудовой деятельности [16].

О.Н. Родина считает, что интегральная оценка успешности деятельности должна обязательно состоять из внутренней и внешней экспертных оценок. При этом внешняя оценка ориентирована на такие характеристики деятельности, как продуктивность, позитивное взаимодействие специалиста с коллегами, а также проявление работником активности и самостоятельности в профессиональной деятельности [12].

С точки зрения Н. А. Батурина, успешность является когнитивно-аффективным оценочным комплексом, который формируется по итогам выполнения профессиональной деятельности с учетом как внешней, так и внутренней оценки результатов этой самой деятельности [2].

В свою очередь, существуют исследования, которые направлены на изучение индивидуально-личностных качеств, являющихся основополагающими для успешности профессиональной деятельности.

В частности, С.Ю. Манухина рассматривает психологические факторы успешности психолога-диагноста кадровой службы и обозначает, что отдельный анализ психологических характеристик какой-либо отдельной сферы может привести к неопределенным результатам. Только исследование взаимного влияния между психологическими сферами сможет раскрыть происхождение успешности или неуспешности каждого конкретного специалиста [17]. Таким понятием, детерминирующим успешность профессиональной деятельности, часто рассматривают понятие «профессионально важные качества», которые «представляют собой отдельные динамические черты личности, психические и психомоторные свойства (выражаемые уровнем развития соответствующих психических и психомоторных процессов), а также 


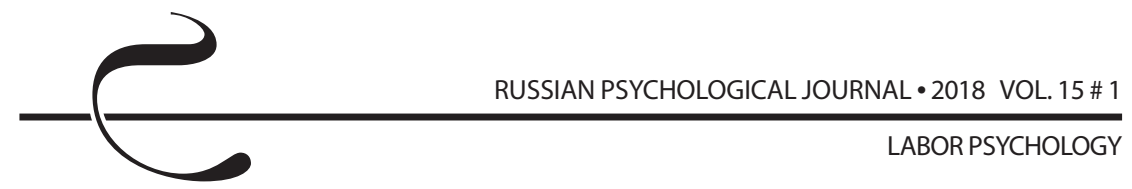

физические качества, соответствующие требованиям к человеку какой-либо определенной профессии и способствующие успешному овладению этой профессией» [13, с. 471]. При этом каждая отдельная профессиональная деятельность предполагает свой определенный комплекс ПВК, которые являются предпосылками успешности выполнения деятельности $[18,19,20]$.

Однако для того, чтобы установить профессиональную успешность, необходимо определить критерии, признаки и степень их сформированности. При этом критерий и признак - это не одно и то же. Критерий - это основание, по которому производятся оценка, установление или классификация чего-либо. Критерии указывают на рассмотрение и анализ определенного явления или процесса. При этом, чтобы зарегистрировать по выделенному критерию конкретное состояние или уровень исследуемого процесса, необходимо понимать, по каким признакам это осуществить. Такими признаками выступают определенные характеристики, находящиеся в границах критерия и позволяющие рассматривать происходящие изменения, т. е. определенные признаки регистрируют какую-либо ситуацию или уровень выраженности исследуемого показателя по конкретному критерию [21, 22]. При этом определение критериев успешности профессиональной деятельности происходит на основании изучения и психологического анализа этой самой деятельности. В роли таких критериев могут быть разнообразные признаки, определяющие достижение необходимых результатов профессиональной деятельности каждым специалистом.

Так как ПВК включают в себя не только категории, имеющие отношение к психологической составляющей, но и физические качества (соматические, морфологические и другие характеристики), то в нашем эмпирическом исследовании под параметрами успешности будем понимать психологические факторы профессиональной успешности.

Однако нередко существует разрыв между ПВК и их проявлением в реальной профессиональной деятельности: «человек, который в процессе обучения быстро и успешно овладел системой необходимых знаний и навыков, в некоторых реально возникающих ситуациях как бы теряет способность их применения в практической работе либо совершает грубые ошибки, которые не могут быть объяснены пробелами в обучении» [23, с. 194]. То есть существующие ПВК, характеризующие потенциальные возможности эффективности деятельности каждого конкретного работника, можно рассматривать применительно к прогнозированию успешности этой самой профессиональной деятельности.

И.В. Бестужев определяет прогнозирование успешности деятельности как систему, состоящую из определенных психологических показателей и имеющих значение для реализации работы. Но в большинстве случаев 
прогнозирование успешности деятельности рассматривается с целью установления пригодности человека к определенному виду деятельности при профессиональном отборе [24]. Прогнозирование успешности деятельности является обоснованным вероятностным итогом, характеризующим персональное поведение каждого человека в будущем. Для научно обоснованного создания персонального прогноза необходимо выработать комплекс прогнозирования успешности профессиональной деятельности [24]. При этом данный комплекс включает определенные этапы: 1) психологическое изучение деятельности; 2) поиск и создание методов получения первичной информации; 3) создание критериев; 4) подготовку принципов перевода первичной информации в единую итоговую диагностическую оценку; 5) определение достоверности и адекватности прогнозирования успешности профессиональной деятельности [24].

Разнообразные стороны успешности профессиональной деятельности также рассматриваются и измеряются с помощью экспертных оценок. Экспертные оценки - популярный способ получения и исследования полученной информации в тех ситуациях, когда невозможно получить объективные данные. Использование оценок продиктовано необходимостью решения определенных задач при отсутствии необходимого отслеживания похожих фактов в прошлом или других объективных данных $[25,26,27,28]$. Метод экспертных оценок отличается высокой степенью предсказания в отношении продуктивности и результативности профессиональной деятельности. Данный метод может использоваться в совокупности с анализом профессиональной деятельности или, несколько ограниченно, для оценки выполняемой профессиональной деятельности. Часто применяемый в зарубежных источниках относительно к оценке работников термин «анализ работы» представляет собой сбор данных, отражающих рассматриваемые профессиональные действия работников, проделанную работу и способы, которые помогли достигнуть итогового результата, а также подтвержденные параметры профессиональной среды, включающие механические, социальные и информационные элементы. Полный «анализ работы» содержит не только выполняемые задачи и обстоятельства, в которых происходит деятельность (условия труда, оборудование), но и также характеристики, необходимые для ее выполнения [29, 30, 31].

В рамках отечественной психологической школы анализ работы в виде показателей, детерминирующих успешность профессиональной деятельности, заключается в определении профессиональной пригодности человека [2]. Анализ профессиональной пригодности предполагает соотнесение разнообразных характеристик работника со специальными требованиями, которые предъявляет конкретная профессиональная деятельность, т. е. «основной 


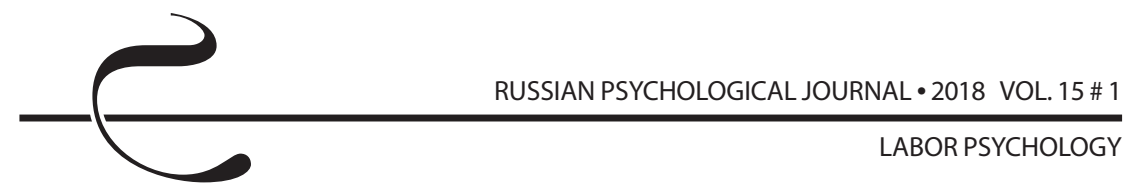

принцип, используемый при оценке деловых, профессиональных и личных качеств специалистов, касается взаимосвязи между характеристиками личности человека и его деятельностью: деятельность формирует многие профессионально значимые качества личности, изучение и оценка которых позволяют сделать вывод о возможностях реализации профессионального потенциала человека и эффективности его деятельности в этой сфере» $[32$, с. 182]. Также в настоящее время большое внимание не только исследователей, но и практиков обращено на сопоставление информации, полученной при помощи разнообразных средств оценивания с фактическими прогностическими возможностями данных средств. Так, в течение продолжительного времени вопросом в дебатах среди исследователей является тот, который охватывает плюсы и минусы применения данных, полученных при использовании стандартизированных методик (тестов) и метода экспертных оценок. Однако стандартизированные методики и тесты при совместном применении с экспертными оценками рассматриваются как дополняющие друг друга методы при проведении профессионального отбора и определения конечного мнения о степени профессиональной пригодности кандидата [22, 33, 34, 35, 36, 37, 38].

Итак, метод экспертных оценок может быть использован для разработки эффективных прогнозов в части, касающейся успешности профессиональной деятельности. В частности, интегральная экспертная оценка деятельности специалистов может выступать в качестве внешнего критерия успешности профессиональной деятельности инспекторов ГИМС МЧС России.

Таким образом, изучение взаимосвязи экспертных оценок и ПВК представляется необходимым в изучении и определении успешности профессиональной деятельности инспекторов ГИМС МЧС России.

\section{Методы}

Изучение взаимосвязи экспертных оценок и ПВК инспекторов ГИМС МЧС России было реализовано в исследовании, в котором приняло участие 275 инспекторов ГИМС МЧС России по субъектам Российской Федерации.

Сбор экспертных оценок на этом этапе представляет собой очередную серию экспертных оценок по определению эффективности деятельности в процессе работы инспекторов и является продолжением исследования по выделению ПВК инспекторов ГИМС МЧС России для прогнозирования успешности их деятельности. Обозначим этапы, по которым ранее были выделены ПВК инспекторов ГИМС МЧС России:

1. Первый этап исследования по выделению ПВК инспекторов ГИМС МЧС России заключался в определении перечня индивидуально-психологических и психофизиологических качеств, способствующих эффективному 
осуществлению профессиональной деятельности инспекторами, а также ряда качеств, препятствующих ее успешному выполнению. В опросных листах группа экспертов, на основании своего мнения, оценивала в качестве ПВК вышеуказанные характеристики и их уровень выраженности. Группу экспертов в количестве 40 человек составляли начальники различных структурных подразделений, отделений, участков ГИМС МЧС России, имеющие стаж по специальности 10 лет и выше.

2. Второй этап представлял собой подбор психодиагностического инструментария, прошедшего массовую апробацию и имеющего практическую ценность с точки зрения прогностичности и валидности результатов. С помощью данного инструментария было проведено психодиагностическое обследование инспекторов ГИМС МЧС России с целью выявления у них наличия и степени выраженности индивидуально-психологических и психофизиологических характеристик, выделенных экспертами в качестве ПВК. Данный этап проводился в период февраль-апрель 2011 г. Было обследовано 275 человек из числа инспекторов ГИМС МЧС России по субъектам Российской Федерации. Средний возраст обследуемых составил $42 \pm 11$ лет. Критерием включения в группу был стаж работы по специальности не менее 3-х лет. Критерием исключения из группы - наличие клинически выраженных акцентуаций в профиле методики многостороннего исследования личности (по Ф.Б. Березину), недостоверные результаты по методикам личностного блока, а также значение среднего арифметического, превышающее $\pm 3 \sigma$. Подобранным инструментарием являются следующие психодиагностические методики: «Тест возрастающей трудности Дж. Равена»; «Интеллектуальная лабильность»; «Стиль мышления» в адаптации А. Алексеева, Л. Громовой; «Кольца Ландольта»; «Числовой квадрат»; «Проба Мюнстерберга»; «Оперативная память»; «Запоминание 10 слов»; «Оценка коммуникативных и организаторских склонностей»; «Оценка уровня субъективного контроля»; «Прогноз»; «Диагностика личностной и реактивной тревожности Ч. Спилбергера, Ю. Ханина» в части, касающейся личностной тревожности; «Ориентировочная анкета»; «Лидерский потенциал»; «Моторная проба Шварцландера»; «16-факторный личностный опросник Кеттелла» (форма А), «Методика многостороннего исследования личности» (по Ф.Б. Березину).

3. Следующий этап заключался в определении эффективности деятельности инспекторов ГИМС МЧС России, прошедших психодиагностическое обследование. Были собраны экспертные оценки на каждого инспектора ГИМС МЧС России, участвовавшего в психодиагностическом обследовании (по 3 экспертные оценки на каждого человека). Это позволило разбить выборку на успешных и неуспешных специалистов. Далее полярные группы подверглись статистической обработке на предмет 


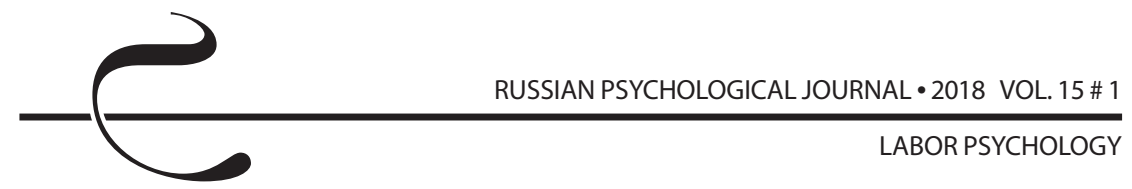

значимых различий с помощью программы IBM SPSS Statistics Version 17, включающей в себя непараметрический критерий «U-критерий Манна Уитни». Данный критерий предназначен для сопоставления показателей, измеренных в одних и тех же условиях на двух выборках обследуемых. Достоверным считался уровень асимптотической значимости $\mathrm{p}<0,05$, свидетельствующий о вероятности того, что статистическая значимость различий случайна не более $5 \%$ [39]. По результатам статистической обработки были установлены достоверные различия между полярными группами по следующим показателям:

- уровень развития базового интеллекта («Тест возрастающей трудности Дж. Равена»);

- абстрактное и оперативное мышление (фактор В по методике «16-факторный опросник Кеттелла», форма A);

- интеллектуальная лабильность (методика «Интеллектуальная лабильность»);

- концентрация внимания (методика «Кольца Ландольта»);

- объем внимания, распределение внимания (методика «Числовой квадрат»);

- объем внимания, избирательность внимания (методика «Проба Мюнстерберга»);

- кратковременная память, долговременная память (методика «Запоминание 10 слов»);

- уровень субъективного контроля (методика «Оценка уровня субъективного контроля»);

- выраженность мужских и женских черт характера (5-я шкала методики ММИЛ по Ф.Б. Березину);

- социальные контакты (0-я шкала методики ММИЛ по Ф.Б. Березину).

Таким образом, результаты значимых различий между полярными группами успешных и неуспешных являются выделенными ПВК инспектора ГИМС МЧС России, достаточными для прогнозирования успешности профессиональной деятельности.

Сбор экспертных оценок для определения их взаимосвязи с ПВК у ранее обследованных инспекторов ГИМС МЧС России проводился в период сентябрь-декабрь 2015 г. Учитывая, что валидность экспертных оценок зависит от профессиональной компетентности эксперта, в группу экспертов были отобраны специалисты, отличающиеся высокой профессиональной компетентностью, знанием специфических особенностей специальности, а также непосредственно работающие с оцениваемыми инспекторами ГИМС МЧС России. В роли экспертов выступали специалисты, занимающие должности руководящего звена и способные оценить эффективность деятельности 
в процессе работы оцениваемых инспекторов ГИМС МЧС России. Оценка происходила по количественному методу, в частности - методу свободной балльной оценки, состоящей в присвоении экспертом определенного количества баллов каждому оцениваемому специалисту с последующим получением интегральной оценки. На каждого оцениваемого инспектора ГИМС МЧС России приходилось по 3 специалиста-эксперта. Опросный лист представлял собой экспертную оценку инспекторов ГИМС МЧС России по 10-балльной шкале, где 1 - минимальная оценка, 10 - максимальная оценка. В качестве оцениваемого параметра выступала эффективность деятельности каждого оцениваемого инспектора ГИМС МЧС России в зависимости от его функциональных обязанностей и выполнения поставленных задач. В качестве критериев оценки можно выделить такие, как: выполнение плановых задач; исполнительность; качество выполняемых работ; уравновешенность, выдержанность; развитые коммуникативные и организационные навыки; умение преодолевать конфликтные ситуации; переработка большого количества информации; переключение с одного вида на другой в условиях дефицита времени; возможность выполнения нескольких действий одновременно; социальная ответственность; соблюдение норм и правил поведения в обществе; сознательное регулирование своих действий, эмоций; стремление к высоким результатам в своей деятельности; самостоятельность; стремление контролировать происходящие события и готовность нести ответственность за принимаемые решения; достаточный уровень обязательности, исполнительности, настойчивости.

\section{Результаты}

Обработка оценок экспертов осуществлялась с помощью среднего значения - для получения интегральной оценки по каждому инспектору ГИМС МЧС России и показателя эффективности деятельности, т. е. по каждому инспектору ГИМС МЧС России интегральная оценка была получена путем суммирования всех полученных оценок на каждого специалиста и последующего разделения на количество экспертов [40]. Получение средних оценок происходило с помощью программы Microsoft Office Excel 2007. На рисунке 1 представлено распределение встречаемости экспертных оценок эффективности деятельности в зависимости от выставляемого каждому инспектору ГИМС МЧС России балла от 1 до 10.

Такой результат свидетельствует о стремлении экспертов использовать все предлагаемые баллы, избегать крайних оценок, и, как правило, не ставить слишком низкие и слишком высокие баллы, поэтому использование 10-балльной шкалы оценки эффективности деятельности является оправданным. 

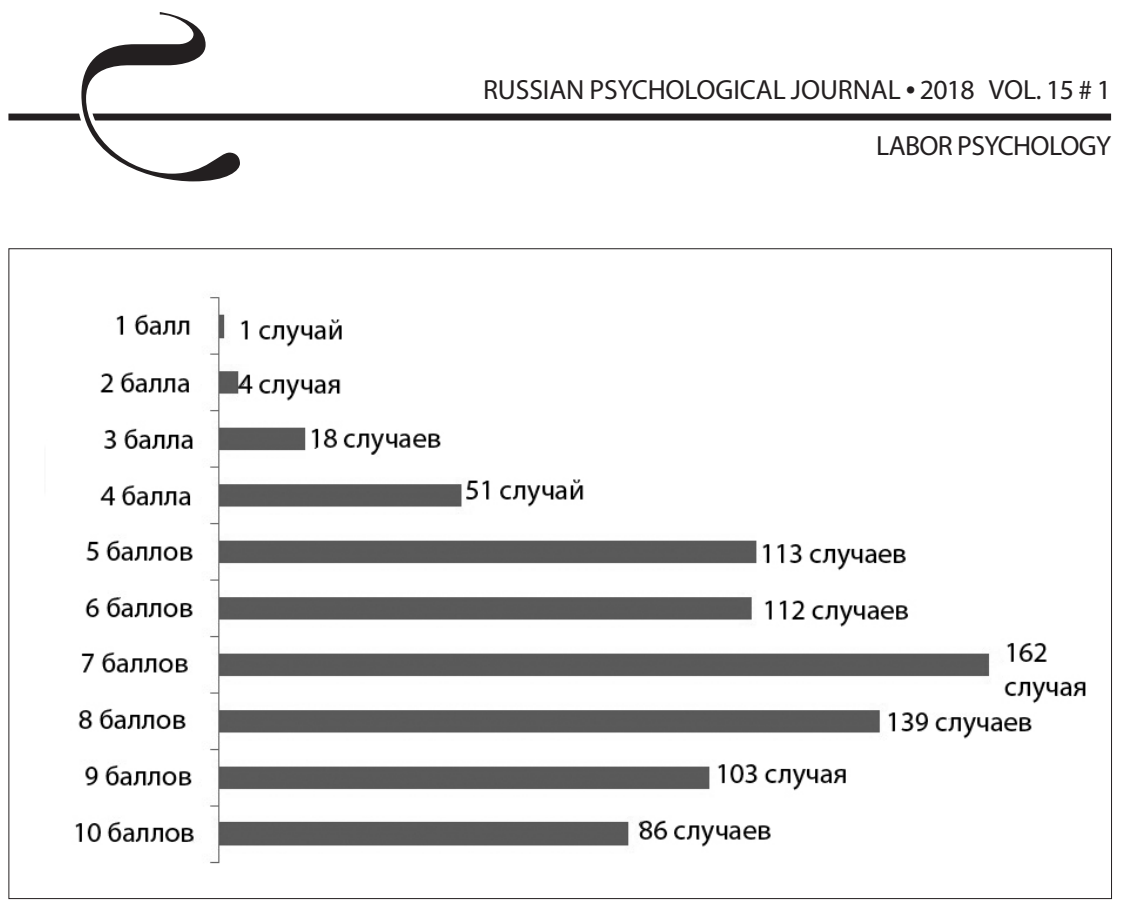

Рисунок 1. Распределение случаев встречаемости экспертной оценки (оценка эфффективности профеессиональной Аеятельности инспекторов ГИМС МЧС России в 2015 г.)

Figure 1. Distribution of expert ratings (evaluation of professional achievement among inspectors in the SSVI of EMERCOM of Russia in 2015)

На основании полученных интегральных экспертных оценок по каждому инспектору ГИМС МЧС России выборка была разделена на специалистов, эффективно выполняющих свою профессиональную деятельность (успешных), и, наоборот, неэффективно выполняющих свою профессиональную деятельность (неуспешных). Для определения взаимосвязи ранее выделенных ПВК и успешности профессиональной деятельности в процессе выполнения профессиональной деятельности инспекторами ГИМС МЧС России был использован корреляционный анализ, предназначенный для определения взаимосвязи между двумя или несколькими переменными, в частности ранговый коэффициент корреляции Спирмена r. Обработка данных происходила с помощью программы IBM SPSS Statistics Version 22. Результаты корреляционного анализа между выделенными ПВК и эффективностью деятельности у инспекторов ГИМС МЧС России представлены в таблице 1.

Взаимосвязь между ПВК внутри группы успешных инспекторов ГИМС МЧС России показана в таблице 2, а взаимосвязь между ПВК внутри группы неуспешных - в таблице 3. 
ПСИХОЛОГИЯ ТРУДА

Таблица 1. Взаимосвязь межАу выделенными ПВК и эфффективностью профрессиональной Аеятельности инспекторов ГИМС МЧС России

Table 1. Relationships among professionally important qualities and professional achievement among inspectors in the SSVI of EMERCOM of Russia

\begin{tabular}{|c|c|c|c|c|}
\hline \multirow[b]{2}{*}{$\begin{array}{c}\text { ПBK } \\
\text { Professionally impor- } \\
\text { tant qualities }\end{array}$} & \multicolumn{2}{|c|}{$\begin{array}{l}\text { Успешные } \\
\text { Successful }\end{array}$} & \multicolumn{2}{|c|}{$\begin{array}{l}\text { Неуспешные } \\
\text { Unsuccessful }\end{array}$} \\
\hline & $\begin{array}{c}\text { Коэфр- } \\
\text { фициент } \\
\text { корреляции } \\
\text { Спирмена r } \\
\text { Spearman's } \\
\text { correlation } \\
\text { coefficient }\left(r_{s}\right)\end{array}$ & $\begin{array}{l}\text { Статис- } \\
\text { тическая } \\
\text { значи- } \\
\text { мость (р) } \\
\text { Statistical } \\
\text { signifi- } \\
\text { cance (p) }\end{array}$ & $\begin{array}{c}\text { Коэф- } \\
\text { фрициент } \\
\text { корре- } \\
\text { Аяции } \\
\text { Спирмена r } \\
\text { Spearman's } \\
\text { correla- } \\
\text { tion coef- } \\
\text { ficient }\left(r_{s}\right)\end{array}$ & $\begin{array}{c}\text { Статис- } \\
\text { тическая } \\
\text { значи- } \\
\text { мость (p) } \\
\text { Statistical } \\
\text { signifi- } \\
\text { cance (p) }\end{array}$ \\
\hline $\begin{array}{l}\text { Уровень раз- } \\
\text { вития базового } \\
\text { интемлекта - Иб } \\
\text { Basic intelligence (BI) }\end{array}$ & 0,139 & 0,05 & 0,121 & - \\
\hline $\begin{array}{l}\text { Интелмектуальная } \\
\text { ^абильность - И^ } \\
\text { Intellectual lability (IL) }\end{array}$ & $-0,226$ & 0,01 & $-0,025$ & - \\
\hline $\begin{array}{l}\text { Концентрация вни- } \\
\text { мания - Квн } \\
\text { Attention } \\
\text { focusing (AF) }\end{array}$ & 0,133 & 0,05 & $-0,113$ & - \\
\hline $\begin{array}{l}\text { Объем внима- } \\
\text { ния («Числовой } \\
\text { кваАрат») - Vвн } \\
\text { Attentional ca- } \\
\text { pacity, by the } \\
\text { Square of Numbers } \\
\text { technique (AC) }\end{array}$ & 0,166 & 0,01 & 0,170 & - \\
\hline $\begin{array}{l}\text { Распределение вни- } \\
\text { мания - Рвн } \\
\text { Attentional } \\
\text { distribution (AD) }\end{array}$ & 0,183 & 0,05 & 0,072 & - \\
\hline
\end{tabular}




\begin{tabular}{|c|c|c|c|c|}
\hline \multirow[b]{2}{*}{$\begin{array}{l}\text { ПBK } \\
\text { Professionally impor- } \\
\text { tant qualities }\end{array}$} & \multicolumn{2}{|c|}{$\begin{array}{l}\text { Успешные } \\
\text { Successful }\end{array}$} & \multicolumn{2}{|c|}{$\begin{array}{c}\text { Неуспешные } \\
\text { Unsuccessful }\end{array}$} \\
\hline & $\begin{array}{c}\text { Коэфо- } \\
\text { фициент } \\
\text { корреляции } \\
\text { Спирмена r } \\
\text { Spearman's } \\
\text { correlation } \\
\text { coefficient }\left(r_{s}\right)\end{array}$ & $\begin{array}{l}\text { Статис- } \\
\text { тическая } \\
\text { значи- } \\
\text { мость (р) } \\
\text { Statistical } \\
\text { signifi- } \\
\text { cance (p) }\end{array}$ & $\begin{array}{c}\text { Коэфо- } \\
\text { фициент } \\
\text { корре- } \\
\text { Аяции } \\
\text { Спирмена r } \\
\text { Spearman's } \\
\text { correla- } \\
\text { tion coef- } \\
\text { ficient }\left(r_{s}\right)\end{array}$ & $\begin{array}{c}\text { Статис- } \\
\text { тическая } \\
\text { значи- } \\
\text { мость (p) } \\
\text { Statistical } \\
\text { signifi- } \\
\text { cance (p) }\end{array}$ \\
\hline $\begin{array}{l}\text { Объем внима- } \\
\text { ния («Проба } \\
\text { Мюнстерберга») Vвн } \\
\text { Attentional capac- } \\
\text { ity, by Munsterberg's } \\
\text { test (AC) }\end{array}$ & 0,090 & - & $-0,015$ & - \\
\hline $\begin{array}{l}\text { Избирательность вни- } \\
\text { мания - Ивн } \\
\text { Attentional } \\
\text { selectivity (AS) }\end{array}$ & 0,186 & 0,01 & $-0,171$ & - \\
\hline $\begin{array}{l}\text { Кратковременная } \\
\text { память (1 повторе- } \\
\text { ние) - КП1 } \\
\text { Short-term memory, } \\
1 \text { repetition (STM1) }\end{array}$ & 0,120 & - & $-0,024$ & - \\
\hline $\begin{array}{l}\text { Кратковременная } \\
\text { память ( } 3 \text { повторе- } \\
\text { ние) - КПЗ } \\
\text { Short-term memory, } \\
3 \text { repetitions (STM3) }\end{array}$ & 0,157 & 0,05 & 0,053 & - \\
\hline $\begin{array}{l}\text { Аолговременная па- } \\
\text { мять - АП } \\
\text { Long-term } \\
\text { memory (LTM) }\end{array}$ & 0,194 & 0,01 & 0,089 & - \\
\hline $\begin{array}{l}\text { Уровень субъективно- } \\
\text { го контроля - УСК } \\
\text { Subjective } \\
\text { control (SC) }\end{array}$ & 0,161 & 0,01 & 0,002 & - \\
\hline
\end{tabular}




\begin{tabular}{|c|c|c|c|c|}
\hline \multirow[b]{2}{*}{$\begin{array}{c}\Pi B K \\
\text { Professionally impor- } \\
\text { tant qualities }\end{array}$} & \multicolumn{2}{|c|}{$\begin{array}{l}\text { Успешные } \\
\text { Successful }\end{array}$} & \multicolumn{2}{|c|}{$\begin{array}{c}\text { Неуспешные } \\
\text { Unsuccessful }\end{array}$} \\
\hline & $\begin{array}{c}\text { Коэф- } \\
\text { фрициент } \\
\text { корреляции } \\
\text { Спирмена r } \\
\text { Spearman's } \\
\text { correlation } \\
\text { coefficient }\left(r_{s}\right)\end{array}$ & $\begin{array}{l}\text { Статис- } \\
\text { тическая } \\
\text { значи- } \\
\text { мость (p) } \\
\text { Statistical } \\
\text { signiff- } \\
\text { cance (p) }\end{array}$ & $\begin{array}{c}\text { Коэф- } \\
\text { фициент } \\
\text { корре- } \\
\text { Аяции } \\
\text { Спирмена r } \\
\text { Spearman's } \\
\text { correla- } \\
\text { tion coef- } \\
\text { ficient }\left(r_{s}\right) \\
\end{array}$ & $\begin{array}{c}\text { Статис- } \\
\text { тическая } \\
\text { значи- } \\
\text { мость (p) } \\
\text { Statistical } \\
\text { signifi- } \\
\text { cance (p) }\end{array}$ \\
\hline $\begin{array}{l}\text { Абстрактное и опе- } \\
\text { ративное мышле- } \\
\text { ние (фрактор В по } \\
\text { метолике «16-фрак- } \\
\text { торный опросник } \\
\text { Кеттемла», орорма A) } \\
\text { Abstract think- } \\
\text { ing and opera- } \\
\text { tory thought (factor B, } \\
\text { Cattel's } 16 \text { Personality } \\
\text { Factors Questionnaire, } \\
\text { form A) }\end{array}$ & 0,198 & 0,01 & 0,300 & 0,05 \\
\hline $\begin{array}{l}\text { Выраженность муж- } \\
\text { ских и женских черт } \\
\text { характера (5-я шка- } \\
\text { ^а по ММИ^) } \\
\text { Masculine and femi- } \\
\text { nine character traits } \\
\text { (scale 5, technique for } \\
\text { multilateral studying } \\
\text { personality) }\end{array}$ & 0,114 & - & 0,050 & - \\
\hline $\begin{array}{l}\text { Социальные контакты } \\
\text { (0-я шкала по ММИА) } \\
\text { Social contacts } \\
\text { (0 scale, technique for } \\
\text { multilateral studying } \\
\text { personality) }\end{array}$ & $-0,224$ & 0,01 & $-0,024$ & - \\
\hline
\end{tabular}




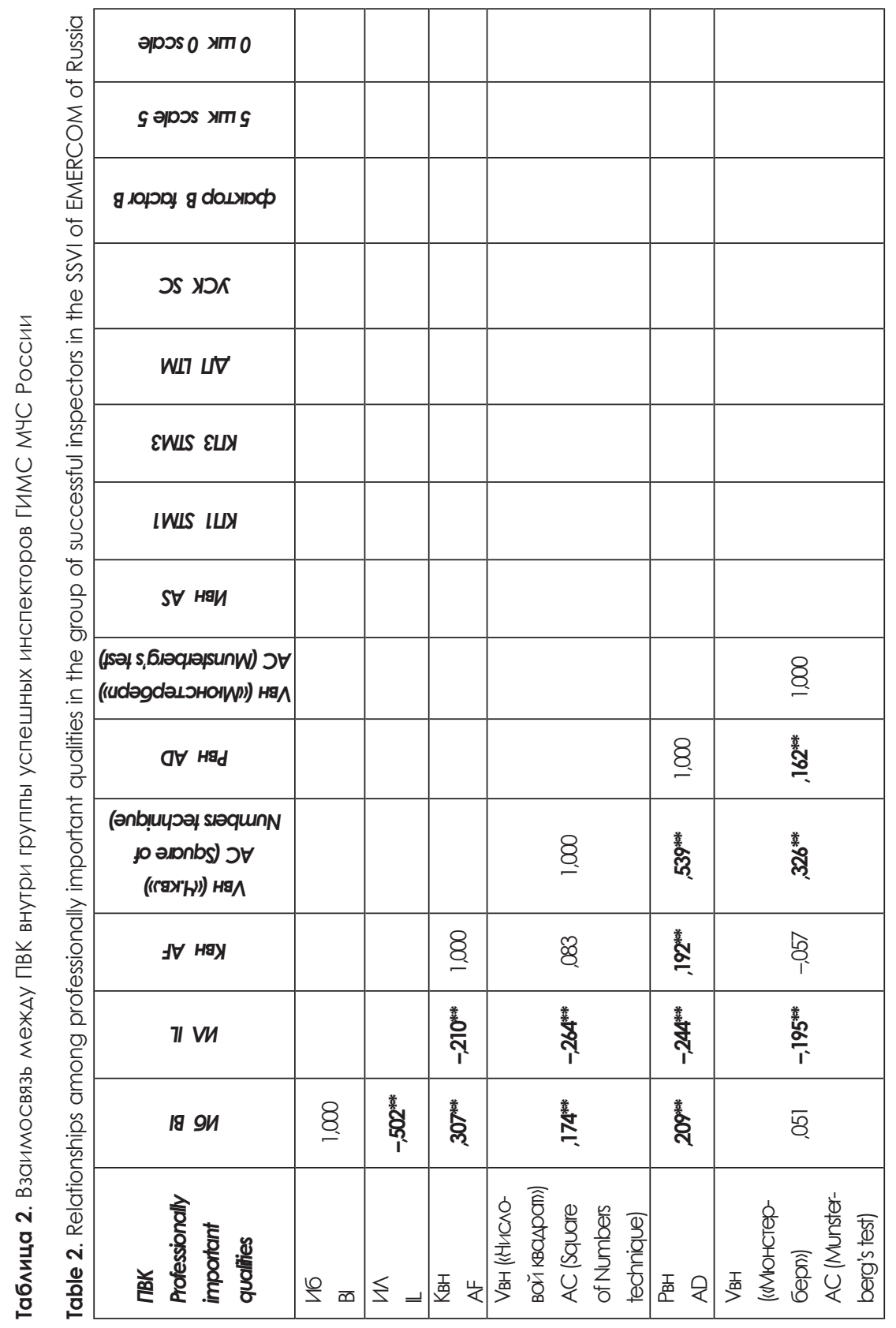




\begin{tabular}{|c|c|c|c|c|c|c|c|}
\hline & & & & & & & 8 \\
\hline & & & & & & 8 & $\overline{8}$ \\
\hline & & & & & $\underset{8}{8}$ & 蒙 & 莡 \\
\hline & & & & 8 & $\stackrel{\text { 歖 }}{-}$ & 8 & 喜 \\
\hline & & & 8 & ชิ & 宓 & $\frac{a}{0}$ & $\frac{\bar{N}}{1}$ \\
\hline & & 8 & 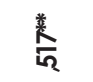 & 요 & 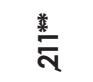 & के & $\stackrel{\Xi}{\stackrel{\Xi}{T}}$ \\
\hline & 8 & 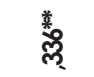 & 㮠 & $\equiv$ & స్ల్ & ஜ్ & ᄋ्? \\
\hline 8 & 㵙 & $\underset{6}{6}$ & 太․ㅗ․ & के & 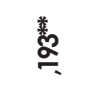 & 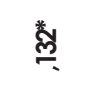 & 우 \\
\hline$\frac{6}{\infty}$ & 卷 & ஜ. & $\ddot{8}$ & $\stackrel{\nabla}{~}$ & $\stackrel{*}{\Xi}$ & $\stackrel{\infty}{8}$ & \$্ \\
\hline 絭 & 으. & $\frac{1}{5}$ & 重 & 8 & 호으 & * & $\frac{a}{\sigma}$ \\
\hline 羬 & $\stackrel{6}{\infty}$ & 亚 & 范 & ฐุ. & ส্ & 粘 & ช్ \\
\hline ㅇ․ & ๖ㅇ & ন্⿳્口 & $\stackrel{5}{E}$ & 능. & : & $\infty$ & \$ \\
\hline 㢈 & $\frac{\text { 墨 }}{\frac{1}{1}}$ & 椟 & $\frac{\text { * }}{\uparrow}$ & $\frac{\text { N }}{\frac{1}{1}}$ & 善 & $\frac{\mathrm{N}}{1}$ & 善 \\
\hline 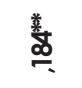 & $\stackrel{*}{\cong}$ & 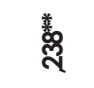 & 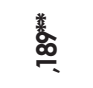 & 瞧 & 范 & : & 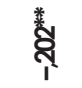 \\
\hline 夁 & 豆 $\bar{\Sigma}$ & 点竞 & ¿ & $\stackrel{\circlearrowright}{\circlearrowright}$ & 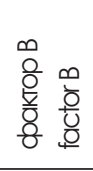 & $\begin{array}{l}\text { 兄 } \\
\text { 当 } \frac{0}{8} \\
\text { 员 }\end{array}$ & 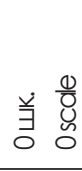 \\
\hline
\end{tabular}




\begin{tabular}{|c|c|c|c|c|c|c|}
\hline & әpDos 0 xm 0 & & & & & \\
\hline 党 & $s$ әрD०s xm $s$ & & & & & \\
\hline u & 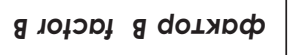 & & & & & \\
\hline 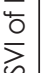 & אכב כת & & & & & \\
\hline 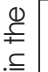 & $W 17 \quad \Delta \nabla$ & & & & & \\
\hline 产 & $\begin{array}{l}\text { EWLS } \\
\text { EUX }\end{array}$ & & & & & \\
\hline 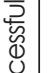 & IWIS IபX & & & & & \\
\hline$\sum^{\frac{2}{2}}$ & S甘 наи & & & & & \\
\hline $\begin{array}{l}3 \\
0 \\
0 \\
0 \\
0\end{array}$ & 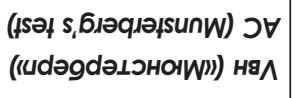 & & & & & \\
\hline 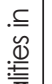 & OV $\mathrm{Hq}_{\mathrm{d}}$ & & & & & 8 \\
\hline $\begin{array}{l}\frac{2}{0} \\
\frac{1}{2} \\
0 \\
0 \\
0\end{array}$ & 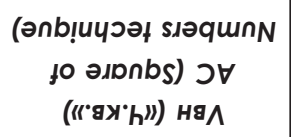 & & & & 8 & 善 \\
\hline $\begin{array}{l}\text { 츨 } \\
\text { 음 }\end{array}$ & I甘 наУ & & & $\underset{8}{8}$ & ৪্ণ & ¿ \\
\hline 这 & 71 vи & & $\underset{8}{8}$ & ્ָત્ & 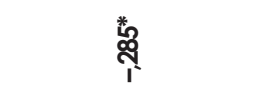 & 啚 \\
\hline 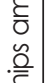 & 1894 & 8 & 善 & 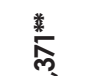 & $\stackrel{2}{2}$ & $\stackrel{20}{0}$ \\
\hline $\begin{array}{l}. \overline{0} \\
\frac{0}{0} \\
\frac{0}{2} \\
m \\
\frac{0}{0} \\
\frac{0}{0} \\
\frac{0}{0}\end{array}$ & 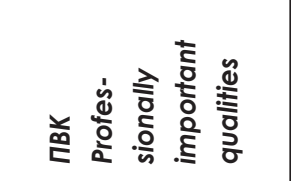 & $\stackrel{0}{\leq} \bar{\infty}$ & $\leqq=$ & 鮃㞸 & 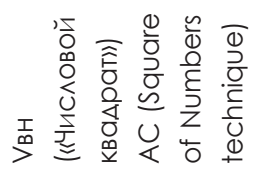 & 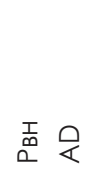 \\
\hline
\end{tabular}




\begin{tabular}{|c|c|c|c|c|c|c|c|c|}
\hline & & & & & & & & $\underset{8}{8}$ \\
\hline & & & & & & & $\underset{8}{8}$ & o \\
\hline & & & & & & $\underset{8}{8}$ & $\stackrel{\infty}{=}$ & $\underset{1}{E}$ \\
\hline & & & & & $\underset{8}{8}$ & $\stackrel{\leftrightarrow}{\stackrel{h}{\longrightarrow}}$ & $\bar{p}$ & 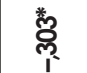 \\
\hline & & & & $\underset{8}{8}$ & $\frac{n}{\sigma_{1}^{\prime}}$ & $\tilde{\sigma}$ & $\stackrel{\Xi}{=}$ & $\overline{\bar{p}_{1}}$ \\
\hline & & & $\underset{8}{8}$ & 善 & $\bar{m}$ & $\stackrel{\cong}{\subseteq}$ & 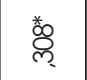 & 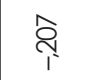 \\
\hline & & $\underset{8}{8}$ & 善 & 善 & $\underset{\text { o }}{\circ}$ & $\sqrt{2}$ & $\cong$ & ơ \\
\hline & $\underset{-}{8}$ & ิે & ભે & ఫิ & $\cong$ & $\check{0}$ & ষ & $\begin{array}{l}\infty \\
\infty \\
i \\
1\end{array}$ \\
\hline$\underset{8}{8}$ & 善 & 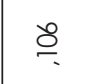 & ๙్ర & 음 & 另 & $\frac{\mathrm{J}}{\mathrm{T}}$ & $\begin{array}{l}\infty \\
\underset{1}{0}\end{array}$ & ?요 \\
\hline 8 & 8 & $\bar{\delta}$ & $\frac{20}{\sigma_{1}}$ & og. & 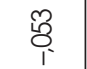 & $\stackrel{\mathrm{s}}{\longrightarrow}$ & 8 & $\stackrel{\infty}{\stackrel{\infty}{-}}$ \\
\hline $\mathscr{\%}$ & $\widetilde{\Xi}$ & สุ & $\stackrel{\mathbb{I}}{\Xi}$ & 㒷 & ఖ & 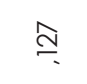 & ঠ & $\stackrel{\text { \& }}{\not}$ \\
\hline$\stackrel{\infty}{\sigma}$ & 莯 & 8 & 㐘 & $\stackrel{9}{\simeq}$ & ম্ন & ষ্ণ & $\stackrel{\infty}{\sim}$ & $\underset{\substack{0 \\
i}}{0}$ \\
\hline ڤ્సે & $\frac{a}{1}$ & $\underset{i}{1}$ & 兽 & $\frac{8}{1}$ & ஜ્ષ & : & ิે & స్లై \\
\hline $\bar{i}$ & $\stackrel{\infty}{\sigma}$ & $\bar{\sigma}$ & $\stackrel{\circ}{\circ}$ & ల్. & ฺָָ & $\frac{1}{\frac{6}{8}}$ & 范 & ${ }_{0}^{\infty}$ \\
\hline 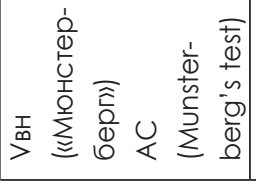 & $\stackrel{\text { I }}{\text { I }}$ & 位 $\bar{\Sigma}$ & 产竞点 & 둔 & $\stackrel{\searrow}{\circlearrowright} \cup$ & 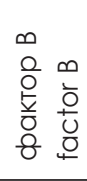 & 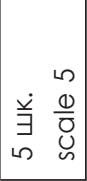 & 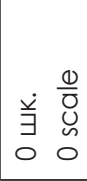 \\
\hline
\end{tabular}




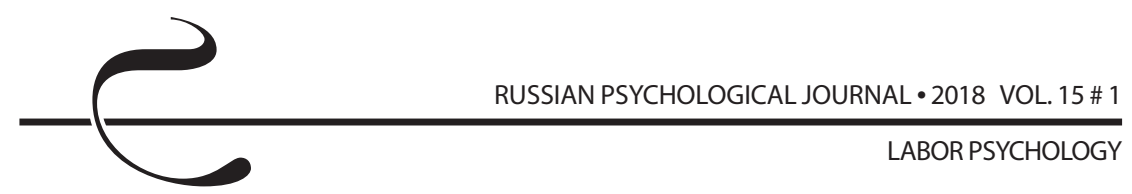

\section{Обсуждение результатов}

По результатам проведенного исследования можно заключить то, что для выполнения инспекторами ГИМС МЧС России своей профессиональной деятельности необходимы ПВК, детерминирующие эффективность выполнения этой самой деятельности.

По итогам корреляционного анализа успешных и неуспешных инспекторов ГИМС МЧС России определена зависимость между выделенными ПВК и эффективностью выполняемой деятельности. В группе неуспешных специалистов существует лишь одно ПВК, которое способствует эффективному выполнению профессиональной деятельности - это «абстрактное и оперативное мышление». Что касается группы успешных специалистов, то установлены статистически значимые корреляции эффективности профессиональной деятельности успешных инспекторов ГИМС МЧС России и таких ПВК, как уровень развития базового интеллекта, абстрактное и оперативное мышление, интеллектуальная лабильность, свойства внимания (концентрация, объем, распределение, избирательность), кратковременная и долговременная память, уровень субъективного контроля, социальные контакты. То есть, чем выше эксперты оценивают эффективность выполняемой профессиональной деятельности инспекторов ГИМС МЧС России, тем выше развиты у таких специалистов уровень базового интеллекта, абстрактное и оперативное мышление, свойства внимания (концентрация, объем, распределение, избирательность), кратковременная и долговременная память. Такие специалисты быстрее переключаются с одного вида деятельности на другой в условиях дефицита времени, способны к установлению большого количества социальных контактов, имеют более развитые коммуникативные навыки, имеют развитый волевой контроль поведения, а также способны к контролю происходящих событий и готовы нести ответственность за принимаемые решения.

Также можно заключить, что успешность деятельности инспекторов ГИМС МЧС России связана со всей структурой ПВК, а не с отдельными показателями; в том числе на успешность деятельности влияет также и связь между ПВК (у успешных специалистов количество связей между ПВК больше, в то время как количество связей между ПВК у неуспешных - меньше).

Проведенное исследование позволило сделать следующие выводы:

1. Анализ профессиональной деятельности инспекторов ГИМС МЧС России позволил выявить трудовые функции, связанные с такими видами деятельности, как: операторская, документационная, контролирующая, организаторская, исследовательская, аналитическая, консультативная, педагогическая, коммуникативная. Все это предъявляет требования не только к профессиональной подготовке данных специалистов, но и к эффективному 
выполнению специалистами своих профессиональных обязанностей.

2. Успешность деятельности является одной из важных характеристик любой профессиональной деятельности. При этом одним из важнейших компонентов личности, необходимых для эффективного и успешного выполнения профессиональной деятельности, являются профессионально важные качества.

3. Для прогнозирования успешности деятельности используется метод экспертных оценок. Интегральная экспертная оценка профессиональной деятельности инспекторов ГИМС МЧС России выступает в качестве внешнего критерия их успешности деятельности.

4. Исследование изучения взаимосвязи ПВК и эффективности выполняемой деятельности инспекторами ГИМС МЧС России проведено с целью обоснования того, что выделенные ПВК являются критерием прогнозирования успешности деятельности инспекторов ГИМС МЧС России.

5. Результаты исследования позволяют заключить, что успешность профессиональной деятельности инспекторов ГИМС МЧС России статистически достоверно связана с такими ПВК, как уровень развития базового интеллекта, абстрактное и оперативное мышление, интеллектуальная лабильность, свойства внимания (концентрация, объем, распределение, избирательность), кратковременная и долговременная память, уровень субъективного контроля, социальные контакты.

6. В то же время успешность профессиональной деятельности инспекторов ГИМС МЧС России связана со всей структурой ПВК, а не с отдельными показателями, при этом связь между самими ПВК также влияет на успешность выполнения инспекторами ГИМС МЧС России своей профессиональной деятельности.

\section{Литература}

1. Бессонова Ю. В. Психологические особенности профессиональной мотивации деятельности в экстремальных условиях // Профессиональная пригодность: субъектно-деятельностный подход / под ред. В. А. Бодрова. - М. : Изд-во ИП РАН, 2004. - С. 113-137.

2. Бодров В.А. Психология профессиональной пригодности. - М. : ПЕР СЭ, 2001. - $511 \mathrm{c}$.

3. Психологические проблемы профессиональной деятельности / под ред. Л. Г. Дикой, А. Н. Занковского. - М. : Наука, 1991. - 166 с.

4. Климов Е. А. Введение в психологию труда. - М. : ИЦ Академия, 2004. $336 \mathrm{c}$.

5. Ананьев Б. Г. О проблемах современного человекознания. - СанктПетербург : Питер, 2001. - 2-е изд. - 272 с. 
6. Братусь Б. С. К проблеме развития личности в зрелом возрасте // Вестник Московского университета. - 1980. - Сер. 14. «Психология». № 2. - C. 3-12.

7. Выготский Л. С. Собрание сочинений в 6 томах. - М. : Говорящая книга, 2004. - Т. 4. Детская психология. - 432 с.

8. Климов Е. А. Психология профессионала: избранные психологические труды. - М. : Изд-во Московского психолого-социального института ; Воронеж : МОДЭК, 2003. - 456 с.

9. Кон И. С. Психология юношеского возраста. - М.: Просвещение, 1979. - 90 с.

10. Обухова Л. Ф. Детская возрастная психология : учебное пособие. - М. : Педагогическое общество России, 2000. - Издание 3-е. - 272 с.

11. Эриксон Э. Идентичность: юность и кризис : учебное пособие : пер. с англ. - М. : Прогресс, 2006. - 2-е изд. - 352 с.

12. Родина О. Н. О понятии «успешность трудовой деятельности» // Вестник Московского университета. - 1996. - Сер. 14 «Психология». - № 3. - С. 60-67.

13. Душков Б. А., Королев А. В., Смирнов Б. А. Психология труда, профессиональной, информационной и организационной деятельности: Словарь / под ред. Б. А. Душкова. - М. : Академический проект, 2005. 3-е изд. - 848 с.

14. Майзель Н. И., Небылицын В. Д., Теплов Б. М. Психологические вопросы отбора // Инженерная психология / под ред. А. Н. Леонтьева, В. П. Зинченко, Д. Ю. Панова. - М. : Прогресс, 1964. - С. 387-396.

15. Толочек В. А. Современная психология труда. - СПб. : Питер, 2010. - 432 с.

16. Дмитриева М. А., Дружилов С. А. Уровни и критерии профессионализма: проблемы формирования современного профессионала // Сибирь. Философия. Образование. - 2000. - № 4. - С. 18-30.

17. Психология труда : хрестоматия : учебно-методический комплекс / автор и составитель С. Ю. Манухина. - М. : Изд. центр ЕАОИ, 2009. - 320 с.

18. Шадриков В. Д. Психология деятельности человека. - М. : Изд-во ИП $\mathrm{PAH}, 2013 .-464 \mathrm{c}$.

19. Шадриков В. Д. Проблемы профессиональных способностей // Психологический журнал. - 1982. - № 5. - С. 13-26.

20. Лаврова Н. А. Влияние личностных особенностей на успешность профессиональной деятельности в системе «человек - человек» // Тезисы московской межвузовской научно-практической конференции «Психодиагностика: области применения, проблемы, перспективы развития» / под ред. М. Ю. Карелиной. - М. : Изд-во МИССО, 2003. - 195 с.

21. Карачарова Ю. А. Психологические факторы профессиональной успешности участкового врача-терапевта : дисс. ... канд. психол. наук. - Тверь, 2010. -211 c. 
ПСИхОЛОГИЯ ТРУДА

22. Хаммер Я. С. Профессиональный успех и его детерминанты // Вопросы психологии. - 2008. - № 4. - С. 147-153.

23. Небылищын В.Д. Психофизиологические исследования индивидуальных различий. - М. : Наука, 1976. - 336 с.

24. Бестужев И. В. Рабочая книга по прогнозированию. - М. : Мысль, 2002. $430 \mathrm{c}$.

25. Бешелев С. Д., Гурвич Ф. Г. Экспертные оценки. - М. : Наука, 1973. - 161 с.

26. Литвак Б. Г. Экспертные оценки и принятие решений. - М. : Патент, 1996. - 271 c.

27. Шошин П. Б. Метод экспертных оценок : Учебное пособие. - М. : Изд-во МГУ, 1987. - 79 с.

28. Conway J. M. Analysis and design of multitrain-multirater performance appraisal studies // Journal of Management. - 1996. - Vol. 22. - P. 139-162. DOI: 10.1016/s0149-2063(96)90015-x

29. Мучински П. Психология, профессия, карьера. - СПб. : Питер, 2004. - 7-е изд. -539 с.

30. Harvey R. J. Job analysis // Handbook of industrial and organization psychology / M. D. Dunnette, L. M. Hough (Eds.). - Palo Alto, CA : Consulting Psychologists Press, 1991. - 2nd ed. - Vol. 2. - P. 71.

31. Levine E. L., Sistrunk F., McNutt K. J., and Gael S. Exemplary job analysis systems in selected organizations: A description of process and outcomes // Journal of Buisiness and Psychology. - 1988. - Vol. 3. - P. 3-21. DOI: $10.1007 /$ bf01016745

32. Почебут Л. Г., Чикер В. А. Организационная социальная психология. Учебное пособие. - СПб. : Речь, 2002. - 298 с.

33. Гуцыкова С. В. Метод экспертных оценок: теория и практика. - М. : Издво ИП РАН, 2011. - 92 с.

34. Day D. V., Silverman S. B. Personality and job performance: evidence of incremental validity // Personnel Psychology. - 1989. - Vol. 42. - P. 25-36. DOI: $10.1111 /$ j.1744-6570.1989.tb01549.x

35. Ericsson K. A., Krampe R. T., Tesch-Romer C. The role of deliberate practice in the acquisition of expert performance // Psychological Review. - 1993. Vol. 100. - P. 363-406. DOI: 10.1037//0033-295X.100.3.363

36. Kleimanx L. S, Biderman M. D., Faley R. H. An examination of employee perceptions of a subjective appraisal system // Journal of Business and Psychology. - 1987. - V. 2. - P. 112-121. DOI: 10.1007/bf01014206

37. Sanchez J. I., De La Torre P. A second look at the relationship between rating and behavioral accuracy in performance appraisal // Journal of Applied Psychology. - 1996. - Vol. 81, № 1. - P. 3-10. DOI: 10.1037//0021-9010.81.1.3 
38. Jackson D. J. R, Stillman J. A., Atkins S. G. Rating tasks versus dimensions in assessment centers: A psychometric comparison // Human Performance. 2005. - Vol. 18. - P. 213-241. DOI: 10.1207/s15327043hup1803_2

39. Наследов А. Д. Математические методы психологического исследования. - СПб. : Речь, 2008. - 392 с.

40. Орлов А. И. Экспертные оценки. Учебное пособие. - М. : Изд-во МГтУ им. Н. Э. Баумана, 2002. - 31 с.

\section{References}

1. Bessonova Yu. V. Psychological features of professional motivation in extreme conditions. In: Bodrov V. A. (ed.) Professional'naya prigodnost': sub"ektno-deyatel'nostnyipodkhod [Professional suitability: a subject-activity approach]. Moscow, Institute of Psychology, Russian Academy of Sciences Publ., 2004, pp. 113-137.

2. Bodrov V. A. Psikhologiya professional'noi prigodnosti [Psychology of professional suitability]. Moscow, PER SE Publ., 2001. 511 p.

3. Dikaya L. G., Zankovskii A. N. (eds.) Psikhologicheskie problemy professional'noi deyatel'nosti [Psychological problems of professional activity]. Moscow, Nauka Publ., 1991. 166 p.

4. Klimov E. A. Vvedenie $v$ psikhologiyu truda [An introduction to labor psychology]. Moscow, Akademiya Publ., 2004. 336 p.

5. Anan'ev B. G. O problemakh sovremennogo chelovekoznaniya [On the problems of modern human study]. St. Petersburg, Piter Publ., 2001. 272 p.

6. Bratus' B. S. On the problem of personality development in adulthood. Vestnik Moskovskogo Universiteta. Seriya 14. Psikhologiya - The Moscow University Herald. Series 14. Psychology, 1980, no. 2, pp. 3-12 (in Russian).

7. Vygotskii L. S. Child psychology. In:Sobranie sochinenii 6 tomakh [Collected works in 6 volumes]. Moscow, Govoryashchaya kniga Publ., 2004, V. 4. 432 p.

8. Klimov E. A. Psikhologiya professionala: izbrannye psikhologicheskie trudy [A professional's psychology: Selected psychological works]. Voronezh, MODEK Publ., 2003. 456 p.

9. Kon I. S. Psikhologiya yunosheskogo vozrasta [The psychology of early adolescence]. Moscow, Prosveshchenie Publ., 1979. 90 p.

10. Obukhova L. F. Detskaya vozrastnaya psikhologiya [Child age psychology]. Moscow, Russian Pedagogical Society Publ., 2000. 272 p.

11. Erikson E. Identity:youth and crisis. New York, W.W. Norton Company, 1968 (Russ. ed.: Erikson E. Identichnost': yunost'i krizis. Moscow, Progress Publ., 2006. 352 p.).

12. Rodina O. N. On the concept of labour achievement. Vestnik Moskovskogo Universiteta. Seriya 14. Psikhologiya - The Moscow University Herald. Series 14. Psychology, 1996, no. 3, pp. 60-67 (in Russian). 
13. Dushkov B. A., Korolev A.V., Smirnov B. A. Psikhologiya truda, professional'noi, informatsionnoi i organizatsionnoi deyatel'nosti [Professional, informational, organizational, and labor psychology]. Moscow, Akademicheskii proekt Publ., 2005. 848 p.

14. Maizel' N. I., Nebylitsyn V. D., Teplov B. M. Psychological problems of selection. In: Leont'ev A. N., Zinchenko V. P., Panov D. Yu. (eds.) Inzhenernaya psikhologiya [Engineering psychology]. Moscow, Progress Publ., 1964, pp. 387-396.

15. Tolochek V. A. Sovremennaya psikhologiya truda [Modern psychology of labor]. St. Petersburg, Piter Publ., 2010.432 p.

16. Dmitrieva M. A., Druzhilov S. A. Levels and criteria of professionalism: Problems of a modern professional's development. Sibir'. Filosofiya. Obrazovanie - Sibir. Philosophy. Education, 2000, no. 4, pp. 18-30 (in Russian).

17. Manukhina S. Yu. Psikhologiya truda [Labor psychology]. Moscow, EAOI Publ., 2009. 320 p.

18. Shadrikov V. D. Psikhologiya deyatel'nosti cheloveka [Psychology of human activity]. Moscow, Institute of Psychology, Russian Academy of Sciences Publ., 2013. 464 p.

19. Shadrikov V. D. Problems of professional abilities. Psikhologicheskii zhurnal, 1982, no. 5, pp. 13-26 (in Russian).

20. Lavrova N. A. Vliyanie lichnostnykh osobennostei na uspeshnost' professional'noi deyatel'nosti v sisteme "chelovek - chelovek"[The effect of personal characteristics on professional achievement in the "human-human"system]. Tezisymoskovskoi mezhvuzovskoi nauchno-prakticheskoi konferentsii "Psikhodiagnostika: oblasti primeneniya, problemy, perspektivy razvitiya" [Proc. Moscow Interuniversity Theoretical and Practical Conference"Psychodiagnostics: applications, challenges, and prospects"]. Moscow, MISSO Publ., 2003. 195 p.

21. Karacharova Yu. A. Psikhologicheskie faktory professional'noi uspeshnosti uchastkovogo vracha-terapevta [Psychological factors of professional achievement among local doctors]. Diss. Cand. Sci. (Psych.). Tver, 2010. $211 \mathrm{p}$.

22. Khammer Ya. S. Professional achievement and its determinants. Voprosy psikhologii, 2008, no. 4, pp. 147-153 (in Russian).

23. Nebylitsyn V. D. Psikhofiziologicheskie issledovaniya individual'nykh razlichii [Psychophysiological researches of individual differences]. Moscow, Nauka Publ., 1976. 336 p.

24. Bestuzhev I. V. Rabochaya kniga po prognozirovaniyu [Workbook on prediction]. Moscow, Mysl' Publ., 2002. 430 p.

25. Beshelev S. D., Gurvich F. G. Ekspertnye otsenki [Expert assessments]. Moscow, Nauka Publ., 1973. 161 p. 


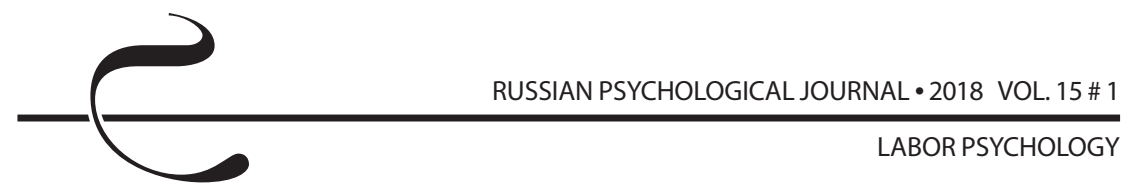

26. Litvak B. G. Ekspertnye otsenki i prinyatie reshenii [Expert assessments and decision-making]. Moscow, Patent Publ., 1996. 271 p.

27. Shoshin P. B. Metod ekspertnykh otsenok [Expert evaluation method]. Moscow, MSU Publ., 1987. $79 \mathrm{p}$.

28. Conway J. M. Analysis and design of multitrain-multirater performance appraisal studies. Journal of Management, 1996, V. 22, pp. 139-162. DOI: 10.1016/s0149-2063(96)90015-x

29. Muchinski P. Psikhologiya, professiya, kar'era [Psychology, profession, and career]. St. Petersburg, Piter Publ., 2004. 539 p.

30. Harvey R. J. Job analysis. In: Dunnette M. D., Hough L. M. (eds.). Handbook of industrial and organization psychology. Palo Alto, CA, Consulting Psychologists Press, 1991, V. 2, p. 71.

31. Levine E. L., Sistrunk F., McNutt K. J., and Gael S. Exemplary job analysis systems in selected organizations: A description of process and outcomes. Journal of Business and Psychology, 1988, V. 3, pp. 3-21. DOI: 10.1007/bf01016745

32. Pochebut L. G., Chiker V. A. Organizatsionnaya sotsial'naya psikhologiya [Organizational social psychology]. St. Petersburg, Rech' Publ., 2002. 298 p.

33. Gutsykova S.V. Metod ekspertnykh otsenok: teoriya i praktika [Expert evaluation method: theory and practice]. Moscow, Institute of Psychology, Russian Academy of Sciences Publ., 2011. 92 p.

34. Day D. V., Silverman S. B. Personality and job performance: evidence of incremental validity. Personnel Psychology, 1989, V. 42, pp. 25-36. DOI: 10.1111/j.1744-6570.1989.tb01549.x

35. Ericsson K. A., Krampe R. T., Tesch-Romer C. The role of deliberate practice in the acquisition of expert performance. Psychological Review, 1993, V. 100, pp. 363-406. DOI: 10.1037//0033-295X.100.3.363

36. Kleimanx L. S, Biderman M. D., Faley R. H. An examination of employee perceptions of a subjective appraisal system. Journal of Business and Psychology, 1987, V. 2, pp. 112-121. DOI: 10.1007/bf01014206

37. Sanchez J. I., De La Torre P. A second look at the relationship between rating and behavioral accuracy in performance appraisal. Journal of Applied Psychology, 1996, V. 81, no. 1, pp. 3-10. DOI: 10.1037//0021-9010.81.1.3

38. Jackson D. J. R, Stillman J. A., Atkins S. G. Rating tasks versus dimensions in assessment centers: A psychometric comparison. Human Performance, 2005, V. 18, pp. 213-241. DOI: 10.1207/s15327043hup1803_2

39. Nasledov A. D. Matematicheskie metody psikhologicheskogo issledovaniya [Mathematical methods of psychological research]. St. Petersburg, Rech' Publ., 2008. 392 p.

40. Orlov A. I. Ekspertnye otsenki [Expert assessments]. Moscow, Bauman Moscow State Technical University Publ., 2002. 31 p. 